\title{
LA CONSTRUCCIÓN DE LA IGLESIA DEL COLEGIO MAYOR DE SAN ILDEFONSO. LAS CAPILLAS Y LAS YESERÍAS
}

Roberto González Ramos

Universidad de Córdoba

Data recepción: 2017/12/13

Data aceptación: 2018/05/17

Contacto autor: roberto.gonzalez@uco.es

ORCID: https://orcid.org/0000-0003-3500-0425

\section{RESUMEN}

La construcción de la iglesia del Colegio Mayor de San Ildefonso concluyó en su estructura básica en 1510. Pero las capillas laterales y las yeserías que decoran el templo empezaron a realizarse desde entonces. Las yeserías, especialmente, han sido estudiadas en varias ocasiones, pero hasta ahora ningún estudio había profundizado en las fuentes documentales de su realización. El presente artículo ofrece una novedosa perspectiva de dichos trabajos atendiendo a lo ya conocido y a la recogida, análisis e interpretación de los datos procedentes de esas fuentes.

Palabras clave: Universidad de Alcalá, iglesia de San Ildefonso, yeserías, arquitectura

\section{ABSTRACT}

Construction of the basic structure of the church of the college of Saint Ildephonsus was completed in around 1510, while work on its side chapels and the plasterwork decorating the church began at around that time. The plasterwork in particular has been studied on various occasions, although no study has as yet dealt with the documental sources of this work in any depth. This article offers a fresh perspective on this construction work, focusing on what is already known and on the gathering, analysis and interpretation of the information originating from these sources.

Keywords: University of Alcalá, church of St Ildephonsus, plasterwork, architecture

La construcción de la iglesia del Colegio Mayor de San Ildefonso de la Universidad de Alcalá de Henares ha sido estudiada en varias ocasiones, con diferentes perspectivas metodológicas y diversos grados de profundidad. Encontramos estudios relativamente superficiales, que han tenido en cuenta las fuentes documentales parcialmente, y otros que se han centrado en analizar distintos aspectos de la obra desde una perspectiva formalista, encuadrados en el estudio del hibridismo estético que se encuentra a principios del siglo XVI en la Península Ibérica, plasmado en el uso de técnicas y fórmulas tradicionales derivadas del arte hispanomusulmán, a las que se unen ti- pos formales del gótico final y procedentes del Renacimiento italiano, fenómeno ampliamente estudiado'.

El estudio del edificio que aquí nos ocupa se ha centrado especialmente en las yeserías decorativas que articulan sus muros en el interior. Sin embargo, en muy pocos casos -y desde luego, no de forma sistemática- se ha realizado acudiendo con detalle a la fuente fundamental que aporta información de primera mano de sus fases constructivas, cronologías, autorías, materiales y coste económico: los libros de cuentas (1509-13 y 1514-18). Lamentablemente, dichos cuerpos documentales datan de al menos nueve años 


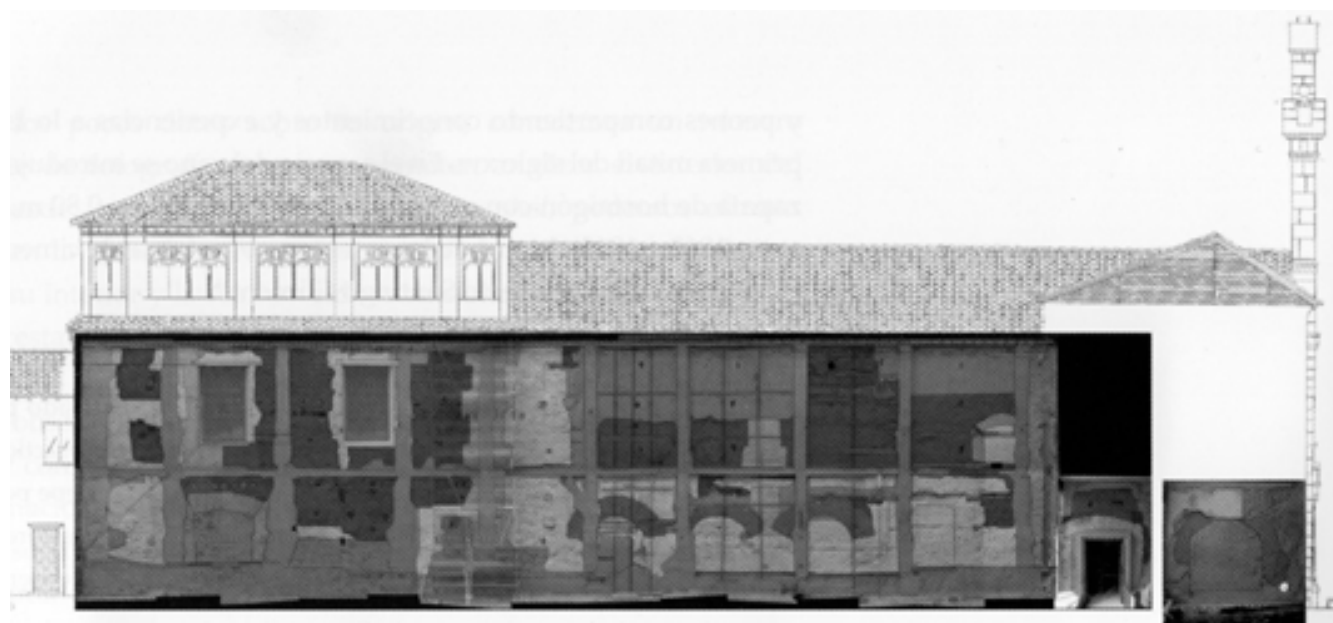

Fig. 1. Estratigrafía del exterior de la Iglesia de San Ildefonso, Alcalá de Henares. Muro del lado del Evangelio, 1500-1510 (J. L. de la Quintana Gordon. 2013. "Materia y significado: las obras de restauración de la manzana fundacional de la Universidad de Alcalá entre 2010 y 2013." En Restauración Contemporánea, J. Rivera, Dir. Alcalá de Henares: Universidad de Alcalá, 238)

después del inicio de los trabajos, lo que nos ha impedido conocer con detalle las primeras fases, desde la cimentación del edificio, pero enseguida comprobaremos que abarcan en su práctica totalidad el proceso de construcción de las capillas y ejecución de las yeserías. El presente trabajo tiene como objetivo principal completar la laguna de información derivada de las circunstancias aludidas. Para ello, se ha realizado un intensivo trabajo de recogida, ordenación, análisis e interpretación de los datos que, como tendremos ocasión de comprobar, aportan gran cantidad de información directa de las obras. Los libros de la fábrica del colegio universidad recogen gran cantidad de pagos, la inmensa mayoría sin ofrecer datos relevantes. Pero hay una importante cantidad de ellos que detallan en distinto grado de profundidad cómo, cuándo y por qué se abonaban, que son los que vamos a interpretar aquí. Aprovecharemos, de paso, las novedades ofrecidas por las excavaciones y estudio de los paramentos que han aportado las últimas labores de restauración del templo, así como lo aportado en estudios previos centrados fundamentalmente en la dotación mobiliaria y litúrgica de su interior. Los resultados del trabajo así expuesto no solamente matizan lo que se ha ido diciendo sobre la construcción y decoración de San Ildefonso, sino que ofrecen una perspectiva muy completa y, en muchas ocasiones inesperada, de ese proceso.

\section{La iglesia de San Ildefonso}

En 1980, el profesor Castillo señalaba que la iglesia del colegio debía estar terminada en lo fundamental en 1510, aunque faltaba su embellecimiento y dotación litúrgica². Los datos que hemos conocido hasta el momento y los que ahora manejamos parecen confirmarlo, pues todos señalan que la estructura básica del edificio se acababa de concluir ese año. De hecho, el 6 de junio de 1510 se pagaba a Alonso de Quevedo y a Juan de Alcaraz por la "carpintería de la azotea que está encima de San Ildefonso" ${ }^{\prime}$. El día 8 de ese mes, a su vez, Pedro Gómez y su hijo cobraban por "quitar una lima que estaba quebrada en la capilla de San Ildefonso" " y Pedro Ruiz de Carranza por "quitar ciertas goteras en San Ildefonso" 5 . Seguramente, con estos trabajos tenga que ver la partida que nos habla de cierto pago del 13 de julio por clavos que suministró Luis de Madrid y por el trabajo de "sacar la tierra y madera del andamio que se hizo en San Ildefonso" ${ }^{\prime}$. La iglesia, efectivamente, estaba concluida en su estructura básica, de una sola nave separada por un arco toral rebajado mixtilíneo de la capilla mayor, ambas cubiertas por sus armaduras de tradición islámica. Pero solamente esa estructura básica estaba realizada. Otros muchos elementos, incluidos algunos arquitectónicos y los decorativos, así como otros necesarios para 
los usos litúrgicos y constitucionales del colegio universidad, estaban sin hacer.

\section{Las capillas}

La finalización de la obra principal parece vislumbrarse, también, en el hecho de que en 1510 una primera campaña de trabajo había proporcionado el retablo principal y los colaterales de la capilla mayor?. Fueron obra del pintor Juan de Borgoña y del entallador Hernando de Sahagún: y tenemos pagos por varales, sortijas y "clanetas" de hierro para el retablo principal, pagados al herrero Francisco de Montoya el 28 de marzo de 1511; para los "retablos pequeños" dio dos varas y dos "sostenientes" que cobró el 6 de octubre de ese año9. El 22 de octubre de 1512 se pagaba el cordel para la cortina del retablo ${ }^{10}$, lo que señalaría que se estaba colocando en su lugar. Pero si esta circunstancia se produjo, esos retablos debieron desmontarse, pues veremos un pago por su colocación muy posterior. Además, se constata que entre octubre y noviembre de 1510 se estaba realizando la reja de separación de nave y capilla mayor, para cuya colocación se abonaba por piedra y basas"1, y por la labor de su dorado el 13 de noviembre de ese año ${ }^{12}$.

Si la estructura de la iglesia puede considerarse terminada en 1510 , casi inmediatamente después de su conclusión se inició la obra de las dependencias laterales, especialmente las capillas de los costados, sobre todo en del lado de la Epístola, y la sacristía, en ese mismo lado. Podemos imaginar, dado que su construcción es inmediata a la conclusión del cuerpo del templo, que en los muros se habían dispuesto los correspondientes arcos de acceso, como los que han aparecido en la última restauración, ocultos en el lado del Evangelio (fig. 1) 13. Esto debe matizarse, pues en ciertos pagos se habla no sólo de la realización de las capillas, sino también de arcos, lo que nos obliga a pensar en que el muro pudo abrirse en ciertos lugares para ellos y que, por lo tanto, las capillas de la Epístola no estaban pensadas en un principio.

En primer lugar, encontramos varias partidas contables referidas a la llegada de materiales para la construcción de esas capillas, y a la obra de cimentación. El 17 de marzo de 1511 se pagaron 1.200 maravedíes (desde ahora "mrs") a Alonso de Budia y a un tal Santander, por 48 carretadas de piedra "que echaron en los cimientos de las capillas de San Ildefonso", y otras 28 carretadas de piedra para lo mismo se abonaron a Bartolomé Rebeco ${ }^{14}$. Otro pago se dio al mismo Budia y a Pedro de Ortego por otras 22 carretadas para las capillas de la iglesia del colegio el 31 del mismo mes $^{15}$. El tal Ortego recibía el 4 de abril la cantidad de 1.400 mrs por 4.000 ladrillos que dio para esta obra' ${ }^{16}$, a los que se sumaron otros 900 el 19 de mayo ${ }^{17}$. También llegaba yeso (12 cahices) y cal (9 fanegas) a la obra de las capillas el 24 del mismo mes ${ }^{18} y$, posteriormente, el día 24, Íñigo de Mendoza y Fernando Colodrero cobraban por otros 6 cahices y 5 fanegas de yeso "que echaron en las capillas de San Ildefonso" ${ }^{19}$. El 7 de mayo Juan Ruano recibía la cantidad de 1.368 mrs por 114 cuartones de madera "que trajo para tomar las aguas de las capillas de San Ildefonso" 20 .

La obra dio comienzo, y Alonso de Toledo recibía el 30 de abril de 1511 la cantidad de 1.000 mrs a cuenta y como parte de pago de "las dos capillas y arcos que hace en San Ildefonso" ${ }^{21}$, el 10 de mayo (aquí como albañil) recibía otros 1.500 mrs "a cuenta de las capillas y arcos" 22 , y el día 21 se le abonaban (ahora como carpintero) 2.100 mrs más "por hacer las dos capillas de San Ildefonso" 23. El día 17 del mismo mes era Juan Pascual el que cobraba 3.055 mrs por las 25 tapias que hizo en las capillas ${ }^{24}$, mientras que Î́nigo de Mendoza cobraba 340 mrs por "sacar la tierra y piedra de las capillas de San Ildefonso" 25 . La labor de "majar granzas" en las mismas capillas se abonó el mismo 17, el 1826, y el 21 de mayo ${ }^{27}$. El día 17 el carpintero Alonso de Quevedo había recibido 1.000 mrs a cuenta y como parte de pago "del destajo de tomar las aguas y suelo sobre la capillas de San Ildefonso" 28 .

Inmediatamente después, el 30 de mayo de 1511, encontramos el pago a Alonso de Toledo de 2.300 mrs, como cumplimiento de pago "de la tercera capilla que hizo en San Ildefonso" 29 , lo que nos da información sobre una estructura más. El 5 de junio era Î́nigo de Mendoza el que cobraba "por sacar tierra y piedra de la capilla tercera de San Ildefonso" ${ }^{30}$. A esto hay que sumar el pago de 1.000 mrs que cobraron Ginés Escoto y Francisco Hormero "por la cuarta capilla de San Ildefonso" el 21 del mismo mes de junio ${ }^{31}$, y el día 


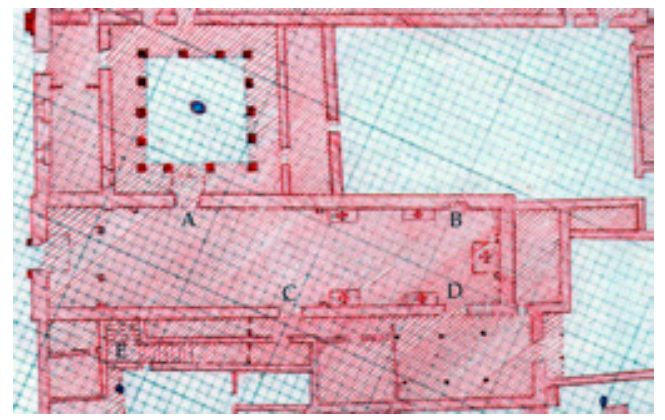

Fig. 2. Planta de la iglesia de San Ildefonso de Alcalá de Henares en 1870 (Quintana Gordon, "Materia y significado," 623)

siguiente se abonaron a Juan de Olmeda y Juan Mayoral 952 mrs más "por el yeso que echaron para hacer la cuarta capilla" ${ }^{32}$, que se nos une a la lista. Una larga partida de pago realizado a Escoto y Hormero nos ayuda a precisar estos trabajos: el 28 de junio se les entregaron 1.300 mrs "por el destajo de la cuarta capilla de San Ildefonso", además otros 300 por ciertos adobes y un "cimiento que hicieron entre la dicha capilla y la escalera por donde bajan a la sacristanía, y de otro tabique que hicieron para bajar al predicatorio" ${ }^{33}$, lo que nos indica que era la última de ese lado, hacia la cabecera, pues lindaba con el púlpito y la zona de la sacristía. El 28 de julio Íñigo de Mendoza cobraba por el destajo "de sacar tierra y piedra de la cuarta capilla de San Ildefonso" ${ }^{34} \mathrm{y}$ el 2 de noviembre Juan Pascual por tres "tapias en las capillas pegadas a la escalera que fue de la sacristía" 35. Todos estos datos nos hablan de la ejecución de hasta cuatro capillas en el muro del lado de la Epístola del cuerpo de la iglesia, la última de ellas en el último tramo que sigue al "predicatorio" o púlpito. Corresponden a los arcos que aún se conservan y que en las fuentes son descritas como estancias abiertas por arcos al cuerpo de la iglesia (figs. 2 y 3$)^{36}$.

El 25 de mayo de 1511, el carpintero Alonso de Quevedo cobraba 1.000 mrs por el suelo del pasadizo de las capillas de San Ildefonso ${ }^{37}$, y el 2 de septiembre otros 550 de dicha moneda "cumplimiento de pago del destajo que tiene hecho de tomar las aguas y del suelo del pasadizo de sobre las capillas" ${ }^{38}$. Se habían pagado poco antes, el día 15 de ese mes, 1.000 mrs a Juan de Durango por el destajo de "echar los suelos a las capillas del pasadizo y hacer las almenas" ${ }_{39}$

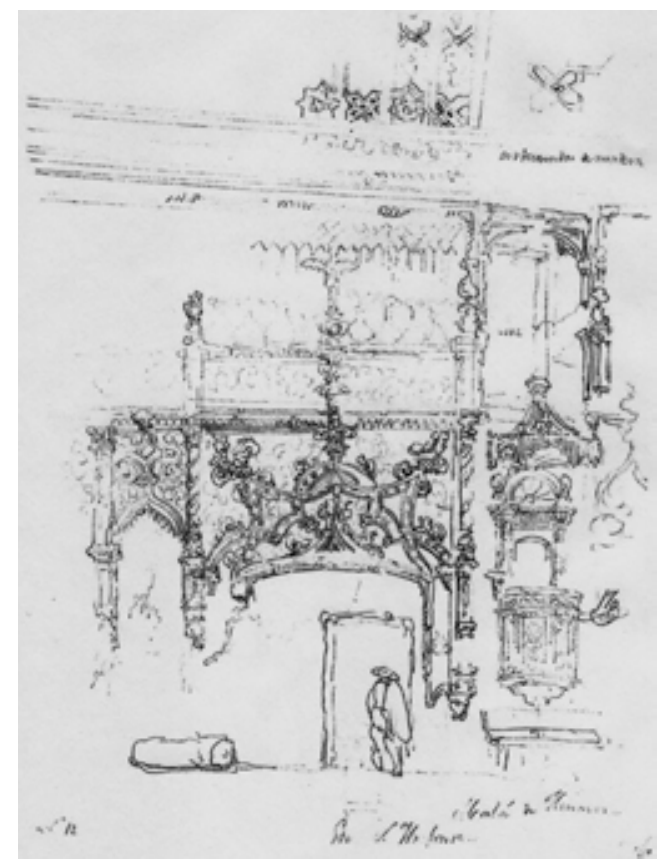

Fig. 3. Jenaro Pérez Villaamil, Yeserías de San Ildefonso de Alcalá de Henares, púlpito y cuarta capilla, c. 1840 (Apuntes de Alcalá: dibujos de Jenaro Pérez Villaamil, Madrid, 2001, 47)

y el 30 de julio recibía otros 500 por el destajo "de hacer de las almenas y tejaroz de sobre las capillas y echar el suelo"40, cobrando 500 más por blanquear dicho pasadizo ${ }^{41}$. El 2 de julio Íñigo de Mendoza cobraba por el yeso que dio para "hacer las escaleras y suelo del pasadizo encima de las capillas"42, mientras el 3 de agosto se pagaba por el yeso empleado en el suelo de dicho pasadizo ${ }^{43}$. Esto señala que, sobre las capillas, o tras ellas, circulaba un pasillo que comunicaría la tribuna, el púlpito, y la sacristía ${ }^{44}$.

A partir de abril de 1510 se construyó la "tribunilla" para los órganos y, posteriormente, compartiendo espacio, la tribuna o coro. Ambos formaron una estructura de madera a los pies de la iglesia, elevada sobre el acceso, a la manera de los típicos sotocoros de la época, con su sillería, realizada por los entalladores Ayllón y Rada. La tribunilla/tribuna, con acceso desde el muro de la Epístola mediante un arco, se hizo entre esa fecha y septiembre del mismo año ${ }^{45}$. Se ha descubierto otra entrada a la estructura desde el lado que correspondía a la vivienda de los capellanes, 


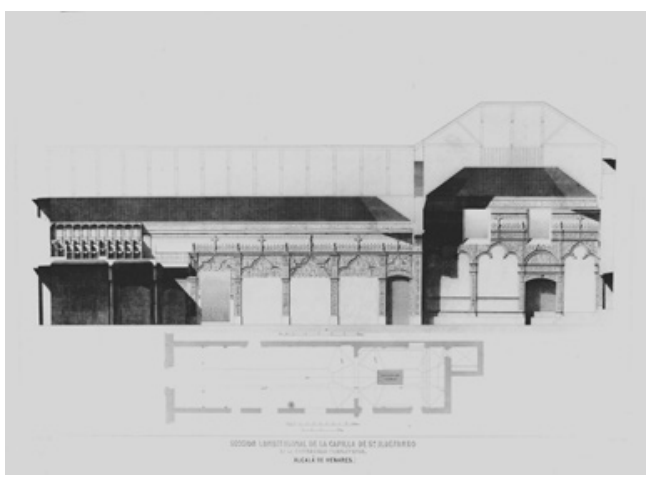

Fig. 4. Planta y sección de la iglesia de San Ildefonso de Alcalá de Henares, 1878 (R. González Ramos, La Universidad de Alcalá de Henares y las artes, Universidad de Alcalá, Alcalá de Henares, 2007, 28)

en el lado opuesto, tapiada en $1889^{46}$. La tribuna propiamente dicha, o coro alto a los pies de la iglesia, aparece realizándose desde enero de 1512. La estructura lignaria condicionó no sólo la amplitud de las capillas, sino también la altura de las yeserías decorativas en los primeros tramos de la nave (fig. 4) ${ }^{47}$.

La obra de las capillas no había concluido en agosto de 1511, como se deduce del hecho de que el 23 de noviembre de ese año se pagara por el traslado de ladrillos "del patio del colegio a la iglesia para las capillas" 48 . De hecho, encontramos otra capilla que sumar a las hasta ahora citadas. El 24 del mismo mes de noviembre se pagaban a Diego de Espinosa 1.000 mrs a cuenta "de la capilla que hace en San Ildefonso a la parte de los cánones"49, es decir, hacia el patio situado entre la iglesia y el bloque principal del colegio, que recibía ese nombre. Otro pago a este Espinosa del 13 de diciembre, por la cantidad de 2.100 mrs, suponía el cumplimiento de pago de los 3.100 en que se había concertado la obra de dicha capilla de la iglesia universitaria "hacia los cánones" ${ }^{50}$. De esta manera descubrimos confirmación documental a lo que las excavaciones de la última restauración realizada en la iglesia han documentado sobre el terreno: el muro del lado del Evangelio del cuerpo de la iglesia presenta tres arcos de ladrillo que corresponden a tres de los tramos de yeserías de los muros y, ante uno de ellos, el más cercano a la capilla mayor, encontramos, hacia el patio lateral, los cimientos de una estancia, que era sin duda la capilla "de los

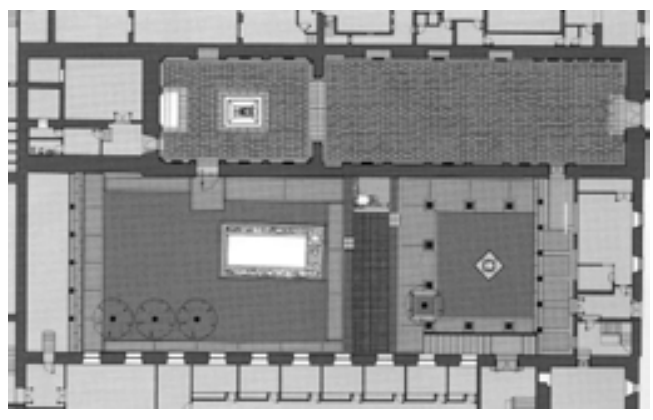

Fig. 5. Planta de la iglesia de San Ildefonso de Alcalá de Henares tras la última restauración. Muestra los cimientos de la capilla "de los cánones" (Quintana Gordon, "Materia y significado," 645)

cánones" (fig. 5). Hubo una capilla en ese lugar, pero sólo una, a pesar de que la existencia de tres arcos ha hecho suponer al restaurador que hasta tres capillas se abrieron en ese lado ${ }^{51}$. Otra cosa es que la existencia de tres arcos permita suponer que hasta tres capillas se habían llegado a planificar en ese lateral, pero sólo una llegó a realizarse. No sabemos cuándo se desmontó y tapió esa capilla del patio de los cánones, aunque a mediados del Seiscientos aún estaba en pie i2 $^{52}$ En diciembre de 1511 encontramos más pagos relacionados con estas obras, como el que recibió Cristóbal de Valverde por hacer "las gradas de las capillas de San Ildefonso y a igualarlas de tierra"53.

Las obras de las capillas continuaron en 1512, lo que sabemos gracias a varios pagos. Diego de Espinosa cobró el 17 de enero 2.000 mrs "por las capilletas e cocina", seguidos el 23 del mismo mes de otra remesa de la misma cantidad y concepto (en este caso capillas y hornos del

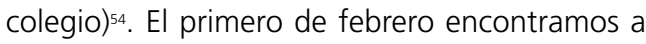
Lope Rodríguez cobrando por dos días que estuvo con un peón trabajando "en el camaracho de las capillas de San Ildefonso", entre otras cosas55. A partir de este momento, Diego de Espinosa aparece cobrando junto a Francisco Hormero: ambos recibieron 1.000 mrs a cuenta el 8 de abril de 1512 por "su destajo de la capilla junto a otra a mano derecha entrando a la iglesia" 56 , el 20 de ese mes de nuevo 1.000 de dicha moneda a cuenta "del dicho destajo de la capilla segunda" ${ }^{57}$ y, el día 28 siguiente 5 ducados (1.875 mrs) "a cuenta de la obra de la capilla de a par de la reja" 58. Luego, aparece un Bernardo de la Vega 


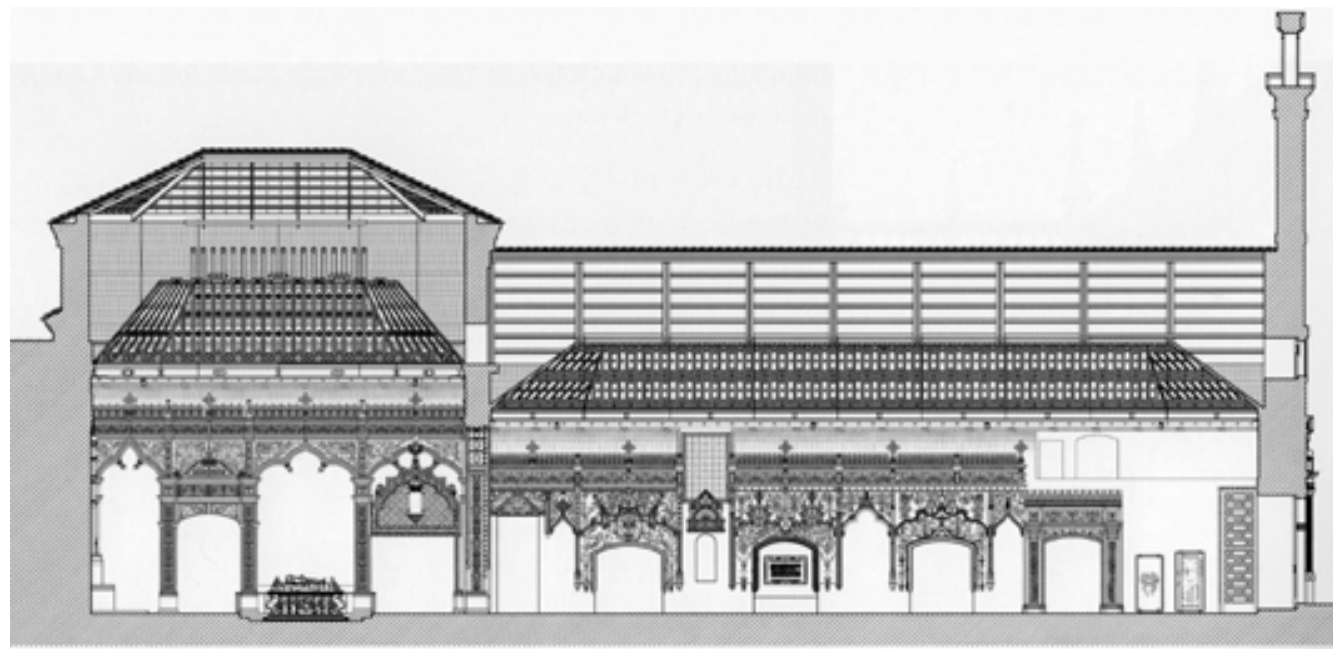

Fig. 6. Sección longitudinal de San Ildefonso de Alcalá de Henares, lado de la Epístola (Quintana Gordon, "Materia y significado," 636)

vecino de Illescas, quien cobró varias cantidades, el 18 de junio "a cuenta de las capillas y escalera de la iglesia de San Ildefonso" 59 . A partir de aquí debemos referirnos al solado de las capillas, que realizó Andrés Sánchez. Este recibió siete pagos por este concepto entre el 18 de abril y el 28 de julio de 1512, sumando un total de $4.400 \mathrm{mrs}$. En uno de los pagos se especifica que se le pagaba por "solar de ladrillo y azulejos en las capillas"60. Los azulejos los trajo de Toledo Francisco de Santorcaz, quien cobró por ello el 6 de marzo y el 30 de octubre ${ }^{61}$.

Podemos ahora confirmar, por si quedaba alguna duda, que las capillas que se citan como primera, segunda, tercera o cuarta, estaban en el muro del lado de la Epístola (fig. 6). Lo extraño es que en 1512 se pague de nuevo por su construcción, especialmente cuando se hace referencia a una capilla junto a otra a mano derecha según se entraba a la iglesia, es decir, a los pies, que será esa segunda capilla, y que ahora encontremos una capilla junto a la reja, que debe tratarse de la cuarta, toda vez que la reja principal se situaba en el arco de separación de nave y capilla mayor.

Las capillas siguieron en obra en 1513, pero ya se habían concluido en su mayor parte. De hecho, encontramos pagos por rematar ciertos aspectos menores o complementarios. El 20 de enero cobraban por su labor en ellas 2.000 mrs
Cristóbal de Valverde y Lope Rodríguez ${ }^{62}$, y el 9 de junio se abonaban 4 ducados (1.500 mrs) a Diego de Espinosa "de la tasación que hizo Pedro de Gumiel maestro mayor de lo que hizo de más" en distintas obras y "capillas de la sacristía y entrada de las capillas"63. Andrés Sánchez, el solador que veíamos antes, recibía el 2 de mayo 525 mrs por, entre otras cosas, traer y colocar "azulejos en los altares de la iglesia del colegio y capillas" ${ }^{64}$. La obra del pasadizo se concluía también entonces (1.000 mrs a Juan de Espinosa el 5 de enero65), así como las puertas de madera de las capillas, cuyos cerrojos se pagaron a Francisco de Madrigal el 18 de junio ${ }^{6}$

La iglesia se iba concluyendo y, el 19 de septiembre de 1513 el albañil Diego de Espinosa cobraba por asentar las pilas de agua bendita ${ }^{67}$, que se pagaron al cantero Diego de Quesada (2 piletas) el 30 de agosto ${ }^{68}$, y para las que el entallador Cristóbal de Ayllón hizo dos pilares de piedra (cobró el 20 de abril de 1514)69. Un vecino de Pinilla y otro de Torrelaguna trasladaban hasta cinco carretadas de losas de piedra desde la villa natal de Cisneros para enlosar "la entrada del colegio a la iglesia"70, piezas de piedra que eran responsabilidad del cantero Juan de la Vega (16 de noviembre y 13 de diciembre de 1513). El cantero García de Cereceda cobraba por asentar "ciertas 
losas en la entrada del patio de los cánones a la iglesia del colegio" el 13 de marzo de 1514¹.

El 10 de mayo de 1513 se pagó al rejero maestre Guillermo por "ciertas poleas que tomó a su cargo hacer para colgar los paños del colegio" 72, y el 2 de julio se especifica en otro pago que dichas poleas estaban destinadas a "los paramentos de la iglesia del colegio"73, elementos que aún se le terminaban de pagar el 4 de febrero de 1514 (se dice eran 29)74, y que son sin duda algunas de las que estaban en lo alto de los muros de la iglesia en unos canes de madera, que han desaparecido tras la última restauración del edificio. El 18 de noviembre de 1515 el carpintero Gil de Requena recibía algún dinero por, entre otras cosas, "los carrillos para entoldar la capilla del colegio"75, es decir, que colocaba las poleas, pues el 19 de marzo del año siguiente se dice que cobraba por "engoznar los carrillos en las perchas para colgar los paños"76.

\section{Las yeserías}

A medida que se fueron levantando las capillas, se iba comenzando la labor de yesería que articularía y adornaría todo el muro de su frente y sus arcos de entrada, así como otras zonas del interior del edificio ${ }^{77}$. Dichas yeserías son la parte más importante y estudiada de la iglesia del colegio Mayor, entre otras cosas por presentar algunos de los ejemplos más tempranos de introducción de los modelos renacentistas en la arquitectura castellana. Sin embargo, su estudio se ha centrado fundamentalmente en sus características formales y, basándose en éstas, se ha intentado explicar su cronología, pues se ha notado también que unas son técnicamente diferentes a las otras y cuentan con referentes formales muy diversos, que van desde el gótico toledano tardío hasta un incipiente Renacimiento a la italiana. Pocos estudios han aportado datos concretos sobre sus autores, precio, fechas de ejecución y otros detalles que pudieran aclarar los documentos conservados con cierta extensión.

El primer pago que tenemos recogido sobre las yeserías de la iglesia del Colegio Mayor data de finales de 1511, coincidiendo, pues, con la conclusión progresiva de la estructura de las primeras capillas, las del lado de la Epístola. De hecho, se trata de una partida muy explícita, que señala que el 21 de diciembre se pagaba 1 ducado (375 mrs) al yesero Cristóbal de Miranda "para cumplimiento del destajo de yesería de las capillas de San Ildefonso de como entran a mano derecha"78, con lo que tenemos la ubicación del trabajo, el nombre del artífice, y su fecha. La partida es confusa en un detalle: que se trataba de "cumplimiento", lo que llevaría a pensar en un último pago y finalización de los trabajos. Pero en los documentos de 1509 y 1510 que conservamos, nada aparece en relación con las yeserías, y mucho menos con Miranda. Es más, enseguida comprobaremos que se le siguieron abonando cantidades por el mismo concepto.

El 15 de enero de 1512 se abonaban a Miranda 15 reales $(510 \mathrm{mrs}$ ) a cuenta de las yeserías de las capillas de San Ildefonso, misma cantidad y concepto que se repetiría el día 26 siguiente $^{79}$. El mismo yesero recibía 30 reales $(1.020$ mrs) el 7 de febrero ${ }^{0}$, otros 1.000 mrs el primero de marzo ${ }^{81}, 2.000$ más el 15 del mismo mes ${ }^{82}$ y la misma cantidad el día 23 siguiente ${ }^{83}$. Cobró por la yesería de las capillas, junto a su compañero Juan de Madrid, 1.500 mrs más el 5 de abril ${ }^{84} \mathrm{y}$ 1.225 el día 9 de este mes ${ }^{85}$. Un yesero llamado Rodríguez había recibido un pago el 21 de enero por "adornar las puertas de la iglesia" y por unos quicios de piedra para la puerta principal y para la de los cánones ${ }^{86}$.

A partir de entonces, los pagos por la yesería de las capillas cambiaron de destinatario, sin que sepamos de las razones de la sustitución de Miranda. El 25 de abril de 1512 se pagaba a Alonso de la Vega y a su hijo, yeseros, "a cuenta de las capillas que han de hacer en la iglesia", la cantidad de $1.000 \mathrm{mrs}^{87}$. Cantidad igual se les pagó el 6 y el 13 de mayo, mientras que el día 20 de ese mes lo abonado ascendió a $1.500^{88}$. Un último pago a de la Vega y su hijo data del 28 de mayo, por $2.000 \mathrm{mrs}^{89}$. De forma que ambos estuvieron trabajando en la yesería de las capillas poco más de un mes, sin que sepamos en esta ocasión, tampoco, de los motivos. Sin embargo, el 16 de mayo aparece recogido por primera vez el nombre del yesero Juan de Santa Cruz, que veremos que junto a su hermano tendría una participación mucho más relevante en la decoración de la iglesia de San Ildefonso ${ }^{\circ}$. Se trata del pago a dicho Santa Cruz de 170 mrs en concepto de "ocho 
días que anduvo su criado a ayudar a amasar yeso"91. Esta partida contable parece indicar que los Santa Cruz, al menos Juan, ya participaban de alguna forma en las yeserías, seguramente bajo la dirección de Alonso de la Vega. El 23 de mayo se dieron otros 100 mrs a Juan de Santa Cruz "por cinco días que anduvo su criado a ayudar en la yesería", el mismo día en que se abonaban otros 150 de esa moneda a Francisco Hormero "por tres mozos suyos que anduvieron tres días a amasar yeso"92, lo que nos habla de buenas cantidades de material que se estaban preparando para disponerse en su lugar.

En estas fechas el púlpito debía estar ya terminado, aunque no encontramos pagos por su ejecución ${ }^{93}$. Sin embargo, el 5 de septiembre de 1512 ya se pagaba por panes de oro para dorarlo y a finales de mes se daba dinero a cuenta al pintor Pozas por su labor en él, que comenzaba entonces. Pero hemos de suponer que no se habrían terminado aún las yeserías que lo enmarcaban, pues no es hasta el 30 agosto de 1513 cuando el cantero Diego de Quesada aparece recibiendo dinero por la realización de la "basa y capitel del púlpito", y por trabajar cinco días asentándolo en su lugar ${ }^{94}$. Entre septiembre y diciembre de 1513 Pozas, con la ayuda de sus compañeros de profesión Cherroa y San Martín, realizaba entonces más labores de dorado, pulido y limpiado del mismo"s. La finalización del "predicatorio" constataría así que el tornavoz del mismo púlpito estaba concluido por entonces, no constando hasta abril y mayo de 1514 la finalización de la ventana, cuando se pagaba por la "vidriera que ha de poner encima del púlpito de la iglesia del colegio" (otro pago del 1 de junio por la vidriera que se "ha de asentar", y el 17 de julio por un total de 64 palmos de vidriera en aquel lugar), a Francisco de Villarroel por "dos marcos con sus pernios que hizo para la vidriera de la ventana encima del púlpito" (1 de junio), y al cerrajero Luis por la "barra de hierro que hizo para poner en la ventana sobre el púlpito del colegio para recibir el mainel y claraboya de la dicha ventana" (8 de junio) ${ }^{96}$.

A partir del 23 de mayo de 1512 encontramos muchos más pagos realizados a de Juan de Santa Cruz, quien cobraba en nombre de sus ayudantes. Por el trabajo de su criado, mozo y/o peón amasando yeso o ayudando en las obras de yesería, Juan de Santa Cruz cobró los días 29 de mayo (120 mrs); 5 (80 mrs.), 10 (120 mrs.), 12 (80 mrs.) y 27 (182 mrs.) de junio; y 4 de julio (100 mrs.), a 20 mrs el día97. El 4 de julio de 1512, un tal Miguel del Campo, por servir a Juan de Santa Cruz cinco días, recibió 5 reales (170 mrs)

La labor de los propios Santa Cruz en la dirección de los trabajos de yesería de las capillas de San Ildefonso se inició el primer día de julio de 1512. Así lo señala una partida que forma parte de una serie de pagos que cubre prácticamente todo el período de su trabajo en la iglesia del Colegio Mayor. Concretamente, una partida del 4 de julio de 1512 señala que el yesero Luis de Santa Cruz recibía 4.166 mrs y medio "para los dos meses de julio y agosto adelantados que Su Señoría le manda dar para que labre en las obras de dicho colegio e donde Su Señoría le mandare a razón de 25.000 por año de que mostró cédula que dice que comenzó a labrar desde primero de julio del año de 1512"99. Enseguida veremos más pagos a sus ayudantes, pero primero atenderemos a los pagos a los maestros ese año, que aparecen registrados juntos en el documento, como decíamos. El 22 de julio Juan de Santa Cruz "su hro" [hermano] (de Luis), recibía 3.333 mrs y medio a cuenta de su trabajo de los meses de julio y agosto ${ }^{100}$. De nuevo Luis de Santa Cruz cobraba por adelantado, el primero de septiembre, esta vez 4.166 mrs y medio por los meses de septiembre y octubre de 1512, y Juan recibía el mismo día 3.333 y medio por el mismo concepto y meses adelantados ${ }^{101}$. El 2 de noviembre se volvía a repetir la operación, cobrando cada uno de los yeseros Santa Cruz por adelantado lo que se había estipulado para los meses de noviembre y diciembre de 1512, esta vez por la cantidad de 1.000 mrs cada uno, pues el 11 de noviembre se entregó, respectivamente, la cantidad de 2.333 mrs y medio a Juan y 3.166 a Luis ${ }^{102}$. El 21 de diciembre de 1512 se volvía a pagar por adelantado a ambos yeseros -partidas y pagos separados, como hasta entonces-, esta vez por los meses próximos de enero y febrero de 1513, suponiendo a Juan la cantidad, de nuevo, de 3.333 mrs y medio, y a Luis de 4.166 y medio ${ }^{103}$. Dicen ambas partidas que los pagos respondían a un compromiso de 20.000 al año para cada uno, lo que no corresponde con lo que antes veíamos. 
En todo este período, también tenemos registrados los pagos a sus mozos, peones y/o ayudantes. Los días 20 de julio de 1512; 7 y 14 de agosto; $2,9,16,24$ y 31 de octubre; 6,20 y 27 de noviembre; y 11, 13, 18, 24 y 31 de diciembre, Luis de Santa Cruz cobraba distintas cantidades por los días que su mozo o criado trabajó en las obras de yesería -con él, hemos de suponer-, sumando un total de $1.540 \mathrm{mrs}$ por 77 días de trabajo de su colaborador ${ }^{104}$. Juan de Santa Cruz cobró por el trabajo de su mozo o criado los días 14,22 y 28 de agosto; 4 y 11 de septiembre; y 18,24 y 31 de diciembre, un total de $720 \mathrm{mrs}$ por 36 días $^{105}$, con lo que tenemos una idea de la importancia de la labor de ambos por vía de lo que trabajaron sus ayudantes, así como que el mozo de Luis no trabajó entre mediados de agosto y principios de septiembre, mientras que el de Juan no consta en octubre y noviembre. También cobró por ayudar a Luis 4 reales (136 mrs.) Miguel del Campo, por 4 días de trabajo -lo que indica que era más que un mozo o criado-el 24 de julio ${ }^{106}$, y el 18 de diciembre Luis de Madrid, mercader, recibía 63 mrs por 7 espuertas, 4 sogas, una palanca y una vara de lienzo "para la yesería" ${ }^{107}$.

Es muy conocida una carta sobre las yeserías que el tesorero de Cisneros, Martínez de Cardeña, envió al prelado para informarle sobre los trabajos, fechada el 19 de octubre de 1512. En ella señala:

Suplico a Vuestra Reverendísima Señoría que me mande enviar algunos cálices que son menester para las capillas en que ahora dicen misa y alguna seda o [f]ustanes para hacer casullas [...]. La obra de la iglesia va muy bien y el púlpito esta dorado y bruñido. Paresçe muy bien no se hará más hasta que Vuestra Señoría lo vea y determine si es servido que se haga todo así, que cierto paresçe muy bien, pero es algo costoso. Santa Cruz es ido a Torrelaguna, su hermano [hro] labra aquí ahora, labra la puerta que sale al patio de los cánones; está por hacer una de las capillas pequeñas de las que están en la capilla mayor y la portada de la puerta de la sacristía; de lo que estaba antes labrado de yeso no se ha tocado nada hasta que Vuestra Señoría lo vea para ver si manda que se derribe y se haga como esto otro para que esté todo conforme. ${ }^{108}$.

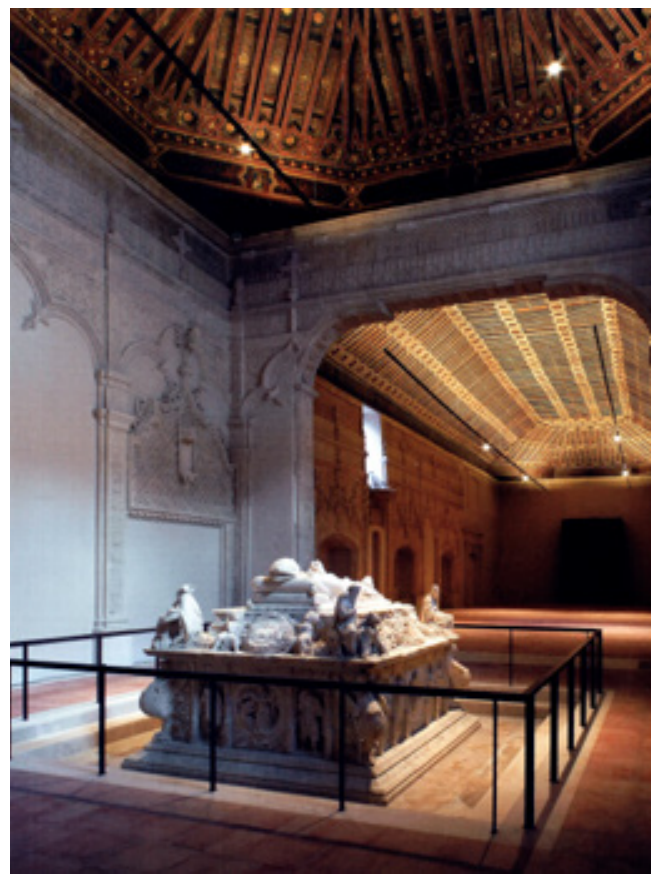

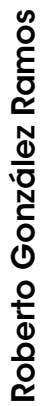

Fig. 7. Interior de la capilla mayor de San Ildefonso de Alcalá de Henares (Quintana Gordon, "Materia y significado," 643)

Podemos comprobar que las capillas ya estaban en uso y, en lo relativo a las yeserías, no hemos encontrado pago alguno por deshacerlas, por lo que hemos de pensar que Cisneros decidió que se dejasen como estaban ${ }^{109}$, aunque esto supusiera una evidente falta de coherencia formal entre ellas. Vemos que Juan de Santa Cruz trabajaba en la nave hacia los pies, en el muro del Evangelio, en la puerta al patio de los cánones (que había recibido quicios de piedra en enero, y se solaría en marzo de 1514), y se trabajaba en la capilla mayor, aunque una de las portadas o "capillas pequeñas" y la portada de la sacristía estaban sin hacer. Sabemos que la portada de la sacristía era la que lleva un pequeño doselete (fig. 7), como señalan diversos documentos ${ }^{110}$ y confirma otro que aportamos ahora. El 13 de marzo de 1515, Andrés Verano cobraba por ciertas imágenes que se hacían en Toledo, entre las que destaca una "de San Pedro de madera para sobre la puerta de la sacristía"111. El pago es tardío, pero sin duda la portada de la sacristía se haría entre la fecha de la misiva y mediados de 1513, pues 


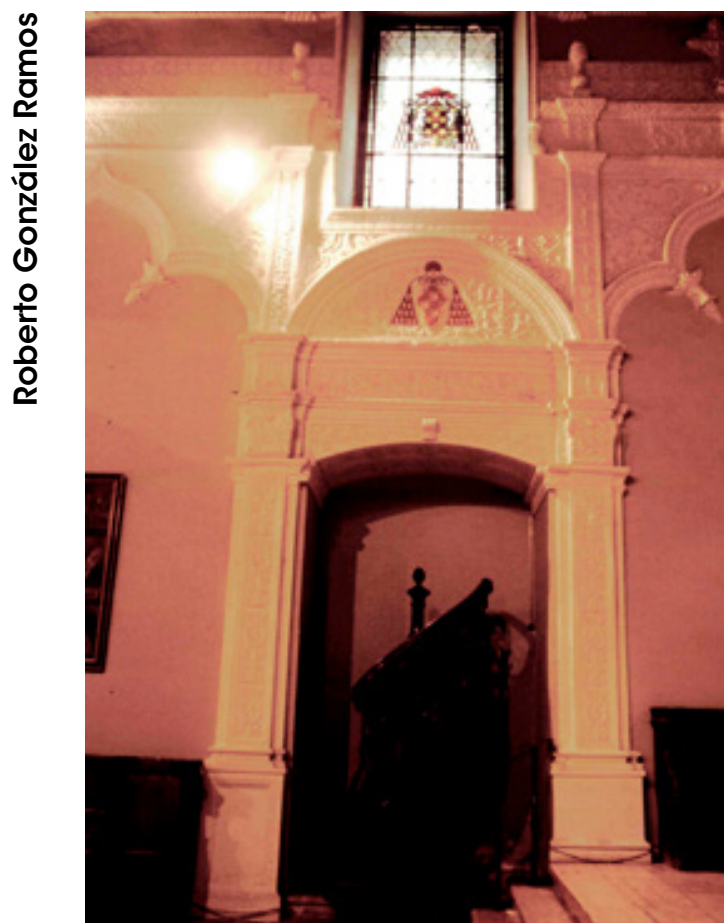

Fig. 8. Iglesia de San Ildefonso de Alcalá de Henares. Capilla colateral del Evangelio, capilla mayor (fotografía del autor)

entre esa fecha y mediados de 1515 no tenemos más pagos por yeserías, como ahora veremos.

El año 1513 los Santa Cruz continuaron su trabajo, más allá de febrero. Cobraron por los meses de marzo y abril, adelantados, ambos cada uno con su partida de pago que lo refleja- el 5 de marzo, sumando Juan 2.786 mrs y medio ("a razón de 25.000 por año sobre ciertas faltas que se le descuentan"), y Luis -"su her [hermano]" 3.790- ("a razón de 25.000 por año sobre ciertas faltas que se le descontaron") ${ }^{112}$. El 2 de mayo siguiente sólo recibía su pago Luis de Santa Cruz, quizás porque Juan trabajaba en Torrelaguna, constando en la partida los $3.821 \mathrm{mrs}$ que se le adelantaban por los meses de mayo y junio de 1513 "sobre 345 que se le quitaron de faltas que hizo su criado que fueron 19 días a 5"113.

En 1513 encontramos, también, gran cantidad de pagos a los criados o colaboradores de Luis y Juan de Santa Cruz, respectivamente. Luis cobró por la labor de su mozo o criado los días 8, 15, 23 y 29 de enero; 6 (dos veces), 12 y 27 de febrero;
$5,12,19$ y 25 de marzo; y 2 y 16 de abril. El 7 de mayo cobró por "tres peones que le ayudaron". Sumó todo 1.556 mrs por 72 días y medio de la labor de su criado"14. Juan, por su parte, cobró por la labor de su mozo los días 8, 15, 23 y 29 de enero; 6, 12, 20 y 27 de febrero, 12, 19 y 25 de marzo; y 2, 9, 23 (dos veces) y 30 de abril. El 26 de marzo cobró directamente su criado por un día "que anduvo con él y de tres peones ese día". Sumaron estos pagos 1.808 mrs, bastante más que los vistos a Luis, por 81 días de trabajo del mozo o criado ${ }^{115}$. El mes de julio de 1513, Juan de Santa Cruz cobraba dos veces, los días 9 y 21 por su labor como oficial de yesería en la obra de "las ventanas de las reliquias de la iglesia", primero 2 ducados (750 mrs) y luego 1 ducado de oro (375 mrs) ${ }^{116}$. Esas ventanas de reliquias se encontraban en la capilla mayor, junto al retablo principal. Entre febrero de 1512 y abril del año siguiente se recogen pagos por las rejas para las capillas, obra de maestre Guillermo, y por la piedra para su colocación, lo que nos habla de que dichos elementos se realizaban al tiempo que las estancias se iban concluyendo, y en ellas se irían colocando, a medida que se terminaban en su estructura y en su decoración de yeserías ${ }^{117}$.

En 1514 no encontramos partida alguna referida a las yeserías de la iglesia de San Ildefonso, quizás porque lo fundamental ya estaba hecho. Sin embargo, el año siguiente vuelven a aparecer, lo que nos habla de nuevas intervenciones. El 6 de junio de 1515 se pagaban al oficial de yesería Gutierre de Cárdenas 100 reales (3.400 mrs.) por la yesería de la iglesia del colegio ${ }^{118}$. Otros 2.500 se le abonaron el día 24 siguiente, especificándose que era "a cuenta de la yesería que hace en la iglesia del colegio"; 2.000 más el 11 de agosto"19; y otros 3.400 se le abonaban por el mismo concepto el 2 de octubre ${ }^{120}$. Su trabajo continuó en 1516, cuando tanto Cárdenas como su compañero Cebrián Alpini recibían 1.700 mrs "cumplimiento de pago de 15.000 de la obra de yesería de la iglesia del colegio", el 9 de febrero, lo que nos habla de la conclusión de los trabajos. Sin embargo, ese mismo año, el 28 de agosto, encontramos a Cárdenas recibiendo $2.250 \mathrm{mrs}$ "por el hacer de las demasías de una coronación en la capilla de la iglesia del colegio sobre la moldura alta" y, el 18 de noviembre, 3.000 más por "la obra de yesería de la capilla de la iglesia 
del colegio"121, sin duda la capilla mayor. Por esta misma labor cobraría aún el 21 de mayo de 1517 (750 mrs.) ${ }^{122}$ y el 6 de agosto de este último año 375 mrs más que eran "cumplimiento de pago de 1.875 que con él se igualó por sentar de las molduras y correr los pilares y paredes de la capilla del colegio" "123. Todo ello nos señala que parte importante de las yeserías de ese ámbito fue realizado por Cárdenas y Alpini, quienes incluso debieron modificar en algunos detalles en la obra de los Santa Cruz. No en vano, uno de los enmarcamientos a manera de portada que eran las capillas pequeñas o colaterales de la capilla mayor (la del Evangelio) presenta unos capiteles, que en su frontera no encontramos, que fueron claramente añadidos o "pegados" sobre las pilastras (de forma que sobresalen de la línea vertical de éstas) (fig. 8). Viendo que se pagó a Cárdenas por asentar molduras y "correr" los pilares y paredes de la capilla, hemos de concluir que las yeserías de los muros, con sus pilastras, fueron obra de este yesero, así como las coronaciones (fig. 9)124.

Podemos comparar las cantidades que hemos ido recogiendo para hacernos una idea tanto de la calidad relativa como de la extensión del trabajo de estos cuatro equipos de yeseros. Miranda aparece cobrando por su labor un total de 10.140 mrs por un trabajo realizado entre -al menos- diciembre de 1511 y abril de 1512, lo que viene a contabilizar cinco meses de trabajo más o menos, alrededor de 2.000 mrs por mes. El mes aproximado de trabajo de Alonso de la Vega le supuso cobrar $6.500 \mathrm{mrs}$ en total, lo que indica seguramente una mejor valoración. Los Santa Cruz, según los pagos que hemos localizado, incluidos los que tienen que ver con sus colaboradores, sumaron la cantidad de 40.967 mrs por un trabajo que abarca el periodo entre mayo de 1512 y marzo de 1513, con extensión a julio de ese año, aunque hemos visto que su dirección de los trabajos se consideraba que empezó en julio de 1512. En todo caso se trataría de un año entero, 12 meses aproximadamente, y una valoración menor por mes que de la Vega. Cárdenas recibió un total de 19.375 mrs en trabajos que se le pagaron entre junio de 1515 y agosto de 1517, aunque, como compaginaba las yeserías de la iglesia con otras labores, esos algo más de 24 meses se refieren a intervenciones más espaciadas, y más difíciles de valorar.

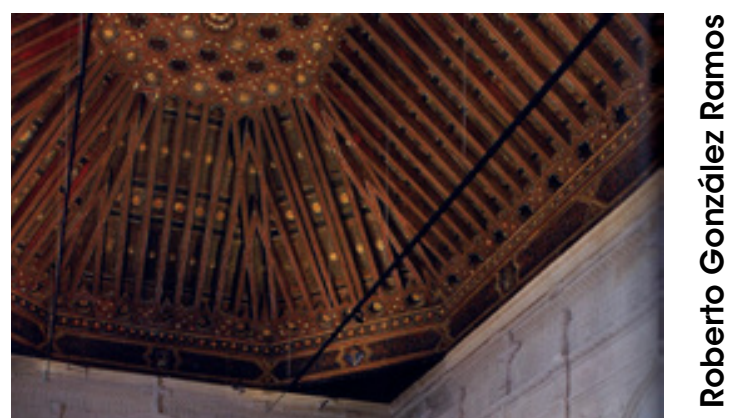

Fig. 9. Interior de la capilla mayor de la iglesia de San Ildefonso de Alcalá de Henares (Quintana Gordon, "Materia y significado," 612)

Podemos deducir, entonces, que la mayor parte de las yeserías fueron, por extensión, obra de los Santa Cruz, especialmente las del lado del Evangelio de la nave y del arco de separación (que no se atribuyen a otros) (fig. 10), las capillas de la capilla mayor y la puerta de la sacristía (como se deduce de la carta), y la zona del púlpito, con su tornavoz y ventana (en función de las fechas de la conclusión del predicatorio y su ventana); que Cárdenas tuvo un papel bastante importante, en segundo lugar, centrado en la capilla mayor -aunque no sólo-, dedicado a sus muros, a los remates altos y -quizás- a ciertos detalles en las capillas colaterales de la misma; el tercero de los yeseros en importancia cuantitativa fue Cristóbal de Miranda, quien trabajaría especialmente en el lado de la Epístola de la nave, en las embocaduras de las capillas de ese lado; la misma zona correspondería a Alonso de la Vega, quien tuvo una intervención más breve -pero no menos intensa- y que, hasta cierto punto, contó con la 


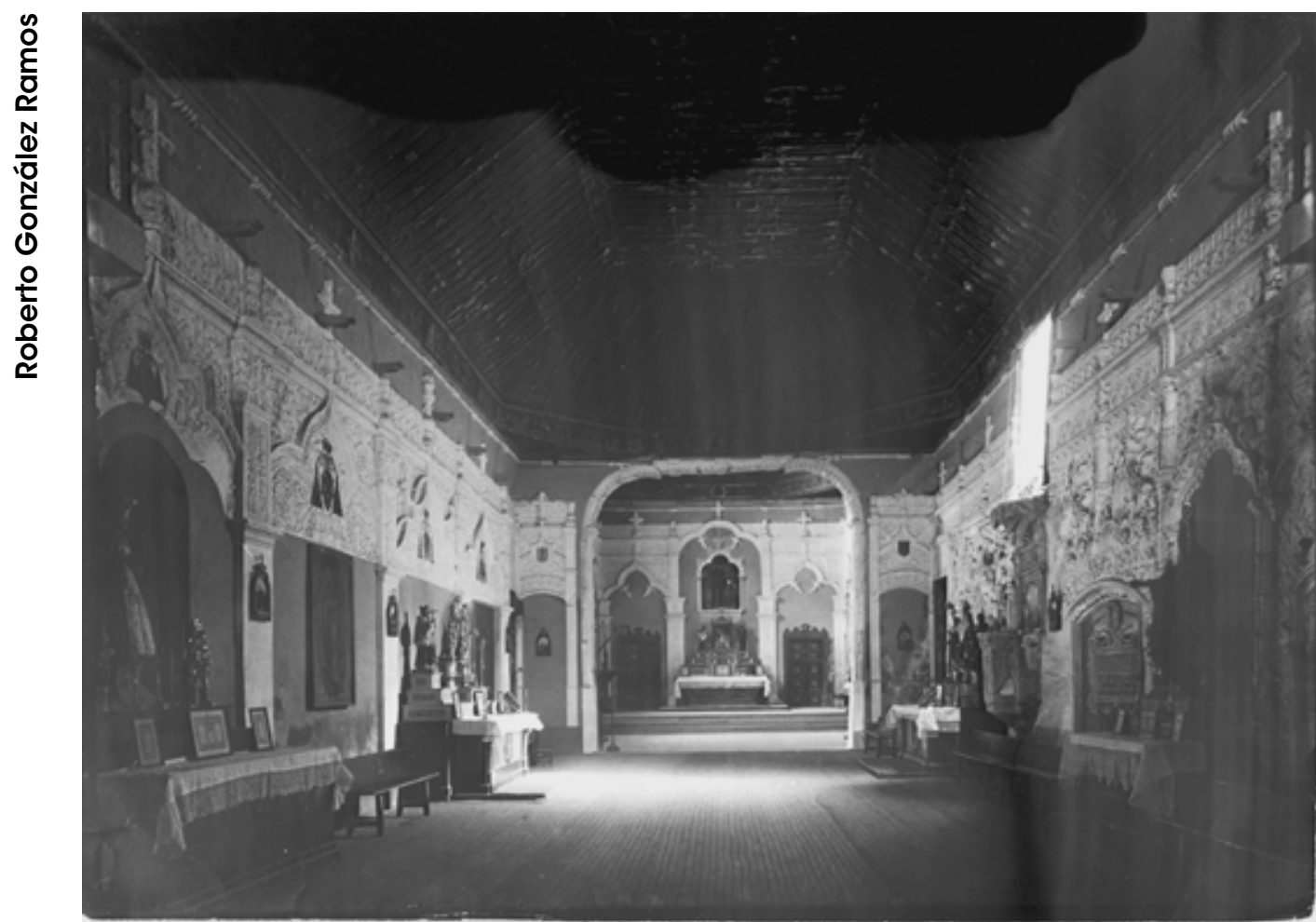

Fig. 10. Interior de la iglesia de San Ildefonso de Alcalá de Henares, inicios del S. XX (Quintana Gordon, "Materia y significado," 621)

colaboración de los Santa Cruz, quienes acabarían sustituyéndolo ${ }^{125}$.

Los pagos realizados a Cárdenas y a Alpini coinciden con los realizados a los pintores. El 20 de septiembre de 1515 Pedro de San Martín recibía dinero para comprar una libra de azul fino "para meter los campos del fenestraje sobre la coronación de la capilla del colegio" 126 y, junto a su compañero Alvarado, el 4 de octubre cobraba a cuenta de la pintura de la iglesia del colegio, y el 8 de noviembre por "la pintura que hacen en lo alto de la Iglesia", cobrando de nuevo el 16 de diciembre ${ }^{127}$, tratándose del friso decorativo con arcos y dentellones que recorre la parte alta de las yeserías, descubierto en la última restauración. El 5 de enero recibían el pago "cumplimiento de 6.500 del pintar de blanco la iglesia de San Ildefonso" 128 .

Los retablos se colocaron en marzo de 1516, cuando se abonaba a un operario por "asentar de los retablos de la capilla mayor de la iglesia del co- legio y de las capillas colaterales de la iglesia" ${ }^{129,}$ a pesar de que el mayor y sus compañeros de dicha capilla mayor (fig. 11) se habían realizado en $1510^{130}$, cuando se colocó el Santísimo en el altar $^{131}$. Los de las capillas colaterales y del cuerpo de la iglesia se hicieron, en dos fases, en 1513 y 1515. Sancho Díaz de Sahagún cobró por ejecutar dos (uno para la cuarta capilla), aunque los pagos y los inventarios hacen sospechar que sólo terminó uno; Ginés López por otro (para la capilla de San Félix y Santiago -hacia los cánones-); y Juan de Borgoña por el grueso de los diez restantes en la segunda fase ${ }^{132}$, lo que podría explicarse por la diferencia de calidad de los artífices o por un aumento en el número de capillas, definidas por los enmarcamientos o recuadros de yeserías además de por estancias laterales. Un total de doce retablos correspondería con las cuatro capillas de la Epístola, la de los cánones y hasta cinco enmarcamientos de yeserías en los muros laterales, a los que hay que sumar dos más en 
los frentes de los tramos de muro que sostienen el arco toral (fig. 10). El contrato firmado por Sancho Díaz indica que debía hacer un retablo de "los mayores" y otro de "los pequeños", lo que señala que había dos modelos, quizás los grandes para el interior de las capillas o los recuadros de yeserías grandes, y los pequeños para los enmarcamientos menores de ambos lados del arco toral y otros que encontramos en el muro de la Epístola de la nave. Es muy probable que sus sucesores en la ejecución de los retablos siguieran parecidas -si no las mismas- instrucciones.

Se ha supuesto que la ampliación del número de capillas y altares podría haber surgido de las indicaciones del propio Cisneros sobre su entierro, futuros sufragios y el número de capellanes de la iglesia del colegio. Pero estos fueron siempre doce (tres mayores y nueve menores), aunque en 1517 se preveía que en ella oficiaran los treinta y tres capellanes del colegio mayor y de los colegios menores ${ }^{133}$. En los primeros inventarios del interior de la iglesia se constata que había diecisiete retablos en sus altares con los dos de la sacristía, quince en la iglesia: el mayor, dos colaterales en la capilla mayor, dos colaterales en el arco de separación de la nave, ya en este espacio, y diez en las capillas y muros de la nave ${ }^{134}$. El número final de éstos no parece corresponderse con el de los capellanes que estaban previstos en las constituciones universitarias para el Colegio Mayor. Por ello, el número de capellanes no explica la necesidad, planteada por lo que parece en 1510, de la construcción de las capillas laterales. Lo extraño es que encontremos cinco capillas-estancia de fábrica, que lo más probable es que tuvieran un retablo cada una, y que el resto de los altares con su retablo se definieran únicamente por el enmarcamiento de yeserías de las paredes. Hemos de advertir que no queda claro si, finalmente, las capillas laterales fueron una ampliación del edificio o se levantaron tras la estructura principal por razones de orden técnico, habiendo estado previstas desde el principio. Desde luego, los arcos de ladrillo que han quedado formando parte del muro del Evangelio indican la intención de que dieran acceso a capillas, aunque en ese lado finalmente sólo se construyó una, quizás para no ocupar en exceso el espacio del patio de los cánones. Los documentos indicarían que el muro

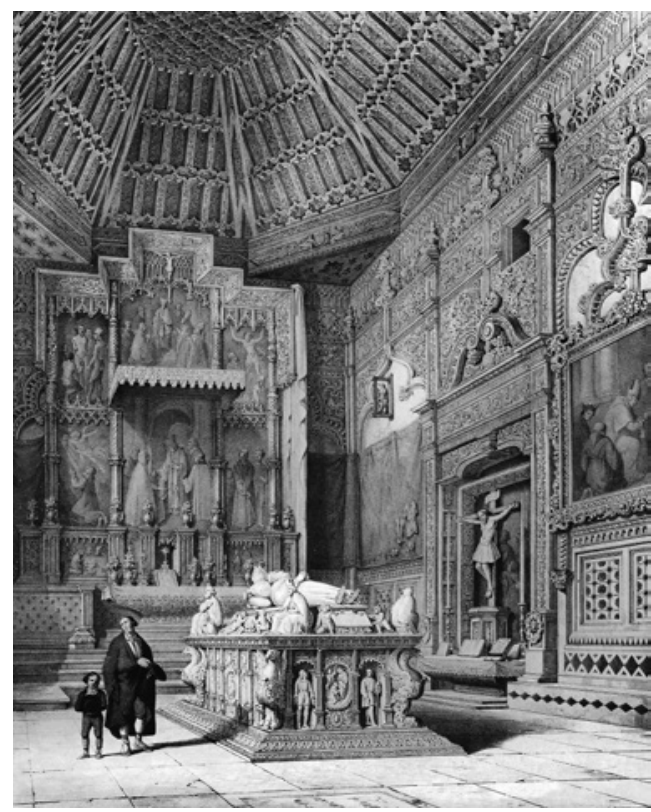

Fig. 11. Grabado del interior de la capilla mayor de la iglesia de San Ildefonso de Alcalá de Henares, J. Pérez Villaamil, 1842 (P. de la Escosura and G. Pérez Villaamil, España artística y monumental, vol. I, Paris, 1842)

de la Epístola fue perforado cuando se iniciaron las capillas de este lado, quizás sustituyendo a las de su frontero.

\section{Conclusiones}

La iglesia del Colegio Mayor de Alcalá estaba concluida, en lo que se refiere a su estructura fundamental, en 1510, y esto queda confirmado. Sin embargo, podemos constatar que hubo un cambio de proyecto a la hora de definir y distribuir las capillas laterales abiertas a la nave. Todo parece indicar que tres capillas estaban previstas en el lado del Evangelio, pero se decidió levantar en su lugar cuatro en el muro opuesto, por lo que los arcos que se conservan insertos en el muro del Evangelio quedaron sin uso, salvo en un caso. Podemos constatar que, a pesar de las conclusiones del restaurador, solo la capilla más cercana al arco triunfal se levantó en ese costado. Las razones tienen que ver seguramente con la construcción del patio adyacente, el de continuos, que ocupó gran parte de ese lado, además de con una ampliación del número de capillas de obra inicialmente previstas en el opuesto. 
Las yeserías fueron realizadas por cuatro yeseros y sus equipos, en al menos tres campañas de ejecución. La primera, que corresponde con las que presentan más tosquedad y formas derivadas del gótico tardío toledano, fue realizada por Cristóbal de Miranda y, después, por Alonso de la Vega y su hijo, entre finales de diciembre de 1511 y finales de mayo de 1512. Una segunda campaña, mucho más extensa, y que corresponde con la aparición de elementos formales renacentistas, por Juan y Luis de Santa Cruz. Al menos Juan ya venía trabajando en las yeserías cuando de la Vega y su hijo estaban ocupados en ellas. Los Santa Cruz debieron ocuparse de terminar las yeserías comenzadas y de extender su labor al muro del Evangelio de la nave y, al menos, las capillas colaterales y la puerta de la sacristía, en la capilla mayor, junto con las yeserías del púlpito y su tornavoz. Su trabajo como responsables -sobre todo Luis de Santa Cruz- de la obra de las yeserías de San Ildefonso se dilató entre julio de 1512 y mayo del año siguiente, aunque en otras zonas Juan siguió trabajando hasta finales de julio -ventanas de las reliquias.

Una tercera campaña data de 1515, encargada a un yesero aún más conocedor de los modelos a la antigua -seguramente debió adecuarse a lo hecho, de ahí sus goticismos-, Gutierre de Cárdenas, autor de las posteriores del Teatro académico o Paraninfo y de las de la sacristía, estas desgraciadamente desaparecidas. Su labor junto a su compañero de posible origen italiano Cebrián Alpini, se centró en la iglesia en las pilastras, molduras y coronamientos de la capilla mayor, y es muy posible que interviniese en modificaciones más o menos ligeras de las yeserías realizadas por los Santa Cruz, como en la colocación de capiteles corintios en la capilla colateral del Evangelio de la misma capilla mayor, y en zonas de la nave (coronación, lado de la Epístola). Seguramente fue el responsable del cambio de la portada de la primera capilla del lado de la Epístola, muy diferente a las de sus hermanas en este lado, y muy correcta en la definición de una portada renacentista.

Estas campañas tienen que ver con las fases de conclusión de las capillas y de distintos elementos litúrgico-mobiliarios de la iglesia, como rejas, púlpito y retablos. Mucho nos tememos que el encargo de los retablos de las capillas, tanto para las formadas por los enmarcamientos de yeserías, como para las capillas de obra, tuvo sus consecuencias en lo que se refiere a las distintas campañas de elaboración de esa decoración y articulación parietal. Lo más sorprendente es que, aunque los Santa Cruz hicieran algunas yeserías "portadas" en la capilla mayor, no fuera hasta 1515 cuando se decorara por completo ese ámbito, y que los retablos que le estaban destinados -incluido el principal-, pagados en 1510, no se instalasen hasta 1516. Este y otros detalles comentados, de nuevo nos hablan de cambios e improvisación, quizás motivada, además de por la premura, por la ausencia en Alcalá de artífices importantes en determinados momentos, como Juan de Borgoña. También es muy posible, a tenor de los datos conservados y teniendo en cuenta los modelos formales desplegados por los sucesivos yeseros, que -aunque se ha puesto en duda- esos modelos tuvieran algo que ver con los diversos cambios y con la aparición sucesiva de los artífices de las yeserías de San Ildefonso. Creemos que es innegable que las yeserías de este edificio fueron algo más que un mero elemento decorativo, pues articularon -y todavía lo hacen- los muros del templo, y se conjugaron con la distribución de retablos y otros elementos y espacios litúrgicos. 
NOTAS

1 E. Tormo, "Cartillas excursionistas Tormo. Alcalá de Henares", Boletín de la Sociedad Española de Excursiones, t. 25, 1917, pp. 143-152. J. Camón Aznar, La arquitectura plateresca, CSIC, Madrid, 1945, I, pp. 37 y 108-109. F. Chueca Goitia, Arquitectura del siglo XVI. Ars Hispaniae XI, Plus Ultra, Madrid, 1953, pp. 130 y 135. J. Cantó Rubio, "Oriente y occidente en el estilo Cisneros", en V Simposio Toledo Renacentista, Colegio Universitario de Toledo, Toledo, 1980, pp. 149-162.B. Pavón Maldonado, Alcalá de Henares medieval. Arte Islámico y mudéjar, Instituto de Estudios Árabes "Miguel Asín"-Asociación Cultural Henares, Madrid, 1982, pp. 131-135. M. A. Castillo Oreja, "La proyección del arte islámico en la arquitectura de nuestro primer Renacimiento: El estilo Cisneros" Anales del Instituto de Estudios Madrileños, t. 12, 1985, pp. 55-63. R. Díez del Corral, Arquitectura y mecenazgo. La imagen de Toledo en el Renacimiento, Alianza, Madrid, 1987, p. 68. F. Marías Franco, El largo siglo XVI, Taurus, Madrid, 1989, pp. 189-192. M. C. Abad Castro, Arquitectura mudéjar religiosa en el arzobispado de Toledo, Caja de ahorro, Toledo, 1991, II, pp. 15-16.

2 M. Á. Castillo Oreja, El Colegio Mayor de San Ildefonso de Alcalá de Henares, Edascal, Madrid, 1980, p. 50.

${ }^{3}$ Madrid, Archivo Histórico Nacional, Sección de Universidades (en adelante AHN, Universidades), libro 744, Libro de cuentas de frutos y rentas y de gastos, 1509-1513, fol. $19 \mathrm{v}$.

${ }^{4}$ AHN, Universidades, libro 744 , fol. $16 \mathrm{~V}$.

${ }^{5}$ AHN, Universidades, libro 744, fol. $108 \mathrm{r}$.

6 R. González Navarro, "Los edificios fundacionales del Colegio Mayor de San Ildefonso y Universidad de Alcalá", en Restauración Contemporánea (J. Rivera, Dir.), Universidad de Alcalá, Alcalá de Henares, 2013, p. 316.

7 R. González Ramos, "Juan de Borgoña y los retablos de la iglesia de San Ildefonso de la Universidad de Alcalá", Madrid. Revista de Arte, Geografía e Historia, t. 3, 2000, p. 387; R. González Ramos, La Universidad de Alcalá de Henares y las artes, Universidad de Alcalá, Alcalá de Henares, 2007, pp. 4042. Véase J. García Oro, La Universidad de Alcalá de Henares en su etapa fundacional (1458-1578), s. e., Santiago de Compostela, 1992, pp. 84 y 87; J. García Oro, El Cardenal Cisneros. Vida y empresas, Biblioteca de Autores Cristianos, Madrid, 1992, t. 1, p. 267.

${ }^{8}$ R. González Ramos, art. cit., p. 387; R. González Ramos, ob. cit., pp. 40-42; J. García Oro, "El primitivo solar académico complutense", Anales Complutenses, t. 2, 1988, p. 75; J. García Oro, La Universidad..., ob. cit., p. 84; J. García Oro, El Cardenal..., ob. cit., p. 38.

9 AHN, Universidades, libro 744 , fols. 125 r y 125 v y 219 r.

${ }^{10}$ R. González Ramos, ob. cit., p. 40.

${ }^{11}$ M. Á. Castillo Oreja, ob. cit., p. 51; R. González Ramos, ob. cit., pp. 50 52.

${ }^{12} \mathrm{AHN}$, Universidades, libro 744, fol. $23 \mathrm{r}$.

${ }^{13} \mathrm{~J}$. L. de la Quintana Gordon, "Materia y significado: las obras de restauración de la manzana fundacional de la Universidad de Alcalá entre 2010 y 2013", en Restauración Contemporánea (J. Rivera, Dir.), Universidad de Alcalá, Alcalá de Henares, 2013, pp. 613-649.

${ }^{14} \mathrm{AHN}$, Universidades, loc. cit., fol. 111 r. Véanse: M. E. Muñoz Santos, Las artes decorativas en Alcalá de Henares, Universidad de Alcalá, Alcalá de Henares, 2002, p. 169 y ss. R. González Navarro, En torno a 1547: la Alcalá de Cervantes, Ed. Alpuerto, Madrid, 2006, p. 175.

${ }^{15} \mathrm{AHN}$, Universidades, libro 744, fol. $111 r$

${ }^{16} \mathrm{lbíd}$.

${ }^{17} \mathrm{AHN}$, Universidades, loc. cit., fol. $117 \mathrm{r}$.

${ }^{18} \mathrm{AHN}$, Universidades, loc. cit., fol. $119 \mathrm{v}$.

${ }^{19} \mathrm{AHN}$, Universidades, loc. cit., fol. $120 \mathrm{v}$.

${ }^{20} \mathrm{AHN}$, Universidades, loc. cit., fol. 113 r. Véase: R. González Navarro, En torno..., ob. cit., p. 175.

${ }^{21} \mathrm{AHN}$, Universidades, libro 744, fol. 96 v. Este pago, a pesar de en- contrarse junto a los mismos de 1511, aparece en la partida como abonado en 1510. Debemos pensar en un error del escribano, pues los demás pagos por las obras de las capillas y su pasadizo son de 1511. R. González Navarro, "Los edificios...", ob. cit., p. 309.

${ }^{22}$ R. González Navarro, "Los edificios...", ob. cit., p. 309

${ }^{23} \mathrm{AHN}$, Universidades, libro 744, fol. $97 \mathrm{r}$.

${ }^{24} \mathrm{AHN}$, Universidades, loc. cit., fol. $106 \mathrm{r}$.

${ }^{25} \mathrm{AHN}$, Universidades, loc. cit., fol. $97 \mathrm{r}$.

${ }^{26} \mathrm{AHN}$, Universidades, loc. cit., fol. $106 \mathrm{r}$.

${ }^{27}$ Ibíd.

${ }^{28}$ R. González Navarro, "Los edificios...", ob. cit., p. 310

${ }^{29} \mathrm{AHN}$, Universidades, libro 744 , fol. $97 \mathrm{v}$.

${ }^{30} \mathrm{AHN}$, Universidades, loc. cit., fol. $106 \mathrm{v}$.

${ }^{31}$ AHN, Universidades, loc. cit., fol. $98 v$.

${ }^{32} \mathrm{AHN}$, Universidades, loc. cit., fol. $121 \mathrm{r}$.

${ }^{33}$ R. González Navarro, "Los edificios...", ob. cit., pp. 312-13.

${ }^{34} \mathrm{AHN}$, Universidades, libro 744, fol. $122 \mathrm{r}$.

${ }^{35} \mathrm{AHN}$, Universidades, loc. cit., fol. $194 \mathrm{~V}$.

${ }^{36}$ R. González Ramos, ob. cit., p. 229.

${ }^{37} \mathrm{AHN}$, Universidades, libro 744, fol. 97 r. Ver nota 20.

${ }^{38} \mathrm{AHN}$, Universidades, loc. cit., fol. $101 \mathrm{v}$.

${ }^{39} \mathrm{AHN}$, Universidades, loc. cit., fol. 97 r. Ver nota 20.

${ }^{40} \mathrm{AHN}$, Universidades, loc. cit., fol. $100 \mathrm{v}$.

${ }^{41}$ AHN, Universidades, loc. cit., fol. $193 \mathrm{~V}$.

${ }^{42}$ R. González Navarro, "Los edificios...", ob. cit., p. 310.

${ }^{43} \mathrm{AHN}$, Universidades, libro 744 fol. $122 r$

${ }^{44}$ El acceso al púlpito, en 1850: A. Lope Huerta, La Sociedad de Condueños, 1850-2000, Centro Internacional 
de Estudios Históricos Cisneros, Alcalá de Henares, 2001, pp. 57, 78-79.

${ }^{45} \mathrm{AHN}$, Universidades, libro 744 , fols. 17 r y 17 v, 18 v, 21 r y 102 v. En parte publicado en: R. González Navarro, "Los edificios...", ob. cit., p. 324.

${ }^{46}$ C. Martín Jiménez, "Los velos de la obra. Lectura de la capilla de San Ildefonso a través de sus yeserías", en Restauración Contemporánea (J. Rivera, Dir.), Universidad de Alcalá, Alcalá de Henares, 2013, p. 558.

${ }^{47}$ R. González Ramos, ob. cit., pp. 49 y 56.

${ }^{48} \mathrm{AHN}$, Universidades, libro 744, fol. $206 r$.

${ }^{49}$ R. González Navarro, "Los edificios...", ob. cit., p. 312.

${ }^{50}$ AHN, Universidades, libro 744, fol. $195 \mathrm{v}$.

${ }^{51} \mathrm{~J}$. L. de la Quintana Gordon, ob. cit., pp. 613-649.

${ }^{52}$ R. González Ramos, ob. cit., p. 87.

${ }^{53} \mathrm{AHN}$, Universidades, libro 744 , fol. $215 \mathrm{r}$.

${ }^{54}$ AHN, Universidades, loc. cit., fol. $197 \mathrm{r}$.

${ }^{55}$ AHN, Universidades, loc. cit., fol. $215 \mathrm{v}$. $199 \mathrm{r}$.

${ }^{56} \mathrm{AHN}$, Universidades, loc. cit., fol. $199 \mathrm{v}$.

${ }^{57} \mathrm{AHN}$, Universidades, loc. cit., fol.

${ }^{58}$ Ibíd.

${ }^{59}$ R. González Navarro, "Los edificios...", ob. cit., p. 315.

${ }^{60} \mathrm{AHN}$, Universidades, libro 744, fols. 199 r, 200 r, 201 r, 202 v, 203 r y $203 \mathrm{v}$.

${ }^{61}$ AHN, Universidades, loc. cit., fol. $531 \mathrm{r}$.

${ }^{62} \mathrm{AHN}$, Universidades, loc. cit., fol. $327 \mathrm{r}$.

${ }^{63} \mathrm{AHN}$, Universidades, loc. cit., fol. $550 \mathrm{v}$.

${ }^{64} \mathrm{AHN}$, Universidades, loc. cit., fol. $531 \mathrm{v}$.

${ }^{65} \mathrm{AHN}$, Universidades, loc. cit., fol. $326 \mathrm{v}$.

${ }^{66} \mathrm{AHN}$, Universidades, loc. cit., fol. $520 \mathrm{v}$.

${ }^{67} \mathrm{AHN}$, Universidades, loc. cit., fol. $552 \mathrm{v}$.
${ }^{68}$ R. González Ramos, ob. cit., p. 54.

${ }^{69} \mathrm{AHN}$, Universidades, libro 744 , fol. $387 \mathrm{r}$.

${ }^{70} \mathrm{AHN}$, Universidades, loc. cit., fol. $538 \mathrm{r}$.

${ }^{71}$ AHN, Universidades, loc. cit., fol. $397 \mathrm{r}$.

${ }^{72} \mathrm{AHN}$, Universidades, loc. cit., fol. $519 \mathrm{r}$.

${ }^{73}$ AHN, Universidades, loc. cit., fol. $523 \mathrm{v}$.

${ }^{74}$ AHN, Universidades, loc. cit., fol. $376 \mathrm{r}$.

${ }^{75} \mathrm{AHN}$, Universidades, libro 745 , Libro de cuentas de frutos y rentas y de gastos, 1514-1518, fol. 37 r.

${ }^{76} \mathrm{AHN}$, Universidades, loc. cit., fol. $155 \mathrm{v}$.

${ }^{77}$ Adelanta la realización de las yeserías a 1509, F. Marías Franco, "Pedro de Gumiel, Francisco de Carabaña, la Universidad de Alcalá y el mito del "estilo Cisneros»", Boletín del Museo e Instituto "Camón Aznar", t. LVIII, 1994, p. 58.

${ }^{78}$ R. González Navarro, "Los edificios...", ob. cit., p. 335.

${ }^{79} \mathrm{AHN}$, Universidades, libro 744, fol. $197 \mathrm{r}$.

${ }^{80} \mathrm{AHN}$, Universidades, loc. cit., fol. $197 \mathrm{v}$.

${ }^{81}$ AHN, Universidades, loc. cit., fol. $198 \mathrm{r}$.

${ }^{82}$ lbíd.

${ }^{83} \mathrm{AHN}$, Universidades, libro 744, fol. $198 \mathrm{~V}$.

${ }^{84}$ R. González Navarro, "Los edificios...", ob. cit., p. 335.

${ }^{85} \mathrm{AHN}$, Universidades, libro 744, fol. $199 \mathrm{r}$.

${ }^{86} \mathrm{AHN}$, Universidades, loc. cit., fol. $207 \mathrm{r}$.

${ }^{87}$ AHN, Universidades, loc. cit., fol. $199 \mathrm{v}$.

${ }^{88} \mathrm{AHN}$, Universidades, loc. cit., fols. 200 r y $200 \mathrm{v}$.

${ }^{89}$ R. González Navarro, "Los edificios...", ob. cit., p. 336.

${ }^{90} \mathrm{M}$. Á. Castillo Oreja, ob. cit., p. 48.

${ }^{91} \mathrm{AHN}$, Universidades, libro 744, fol. $209 \mathrm{r}$.

${ }^{92}$ lbíd.
${ }^{93}$ Sobre el púlpito, con referencias anteriores, R. González Ramos, ob. cit., pp. 53-55.

${ }^{94}$ Ob. cit., p. 54.

${ }^{95}$ Ob. cit., p. 55.

${ }^{96} \mathrm{AHN}$, Universidades, libro 744, fols. 377 r, 404 r, 405 v y 408 v. R. González Ramos, ob. cit., p. 49. R. González Navarro, "Los edificios...", ob. cit., p. 328.

${ }^{97} \mathrm{AHN}$, Universidades, libro 744, fols. $209 \mathrm{v}, 210$ ry $210 \mathrm{v}$.

${ }^{98} \mathrm{AHN}$, Universidades, loc. cit., fol. 211 r. Más sobre los Santa Cruz, en F. Marías Franco, art. cit., p. 59. P. Navarro Echeverría, "Presencia toledana en las yeserías mudéjares aragonesas del siglo XVI", Sharq al-Andaluls, t. 12, 1995, p. 521.

${ }^{99}$ R. González Navarro, "Nuevas aportaciones a medio siglo de construcción universitaria en Alcalá de Henares (1510-1560)", Anales Complutenses, t. I, 1987, p. 160; J. García Oro, El Cardenal..., ob. cit., p. 376; R. González Navarro, "Los edificios...", ob. cit., p. 336.

100 AHN, Universidades, libro 744 , fol. 244 r.

101 AHN, Universidades, loc. cit., fol. $244 \mathrm{v}$.
102 Ibíd.
103 Ibíd.
104 AHN, Universidades, loc. cit., fols. 211 r, 333 r, 333 v, 335 r-338 r.

105 AHN, Universidades, loc. cit., fols. 333r-334r, 337r y v.

106 AHN, Universidades, loc. cit., fol. $211 \mathrm{r}$

107 AHN, Universidades, loc. cit., fol. 244 r.

108 M. Á. Castillo Oreja, ob. cit., p. 50. J. García Oro, El Cardenal..., ob. cit., pp. 262-263. Corrigen la fecha, J. Meseguer Fernández, El Cardenal Cisneros y su villa de Alcalá de Henares, Institución de Estudios Complutenses, Alcalá de Henares, 1982, pp. 100 y 125-126. F. Marías Franco, art. cit., pp. 58-59. La participación de los Santa Cruz en Torrelaguna en M. Estella Marcos, "Noticias artísticas de Torrelaguna", Boletín del Seminario de Arte y Arqueología, t. 51, 1985, pp. 305-317. 
109 Como ya sospechaba M. Á. Castillo Oreja, ob. cit., p. 50. También en: F. Marías Franco, art. cit., pp. 60-61.

110 R. González Ramos, ob. cit., p. 439.

AHN, Universidades, libro 745, fol. 47 v. R. González Ramos, ob. cit., p. 58.

112 AHN, Universidades, libro 744 , fol. 345 r.

113 AHN, Universidades, loc. cit., fol. $569 \mathrm{v}$.

$114 \mathrm{AHN}$, Universidades, loc. cit., fols. 338 r-340 r, 341 r y v, y 545 $r-546 r$.

115 AHN, Universidades, loc. cit., fols. 338 r-340 r, 341 r, y 545 r-546 r.

116 AHN, Universidades, loc. cit., fols. 561 v y 562 v.

117 R. González Ramos, ob. cit., pp. 52-53. Con más bibliografía sobre Cárdenas: E. Dolphin, Archbishop Francisco Jiménez de Cisneros and the Decoration of the Chapter Room and Mozarabic Chapel in Toledo Cathedral, UMI, Ann Arbor, Michigan, 2008, p. 115; R. González Ramos, La Aldehuela de Torrelaguna. Granja, Colegio, residencia de la Universidad de Alcalá, Universidad de Alcalá, Alcalá de Henares, 2016, p. 65.
118 R. González Ramos, La Universidad..., ob. cit., p. 32.

119 AHN, Universidades, libro 745, fol. $18 \mathrm{r}$.

120 AHN, Universidades, loc. cit., fol. $20 \mathrm{r}$.

121 R. González Ramos, La Universidad..., ob. cit., p. 32.

122 AHN, Universidades, libro 745 , fol. 262 v.

123 AHN, Universidades, loc. cit., fol. 264 r.

124 F. Marías Franco, art. cit., p. 61, ya vio en el friso y la crestería de, al menos, el lado de la Epístola de la nave, una intervención mediante la que "se unificara toda la composición por medio del friso y la crestería de relleno y cierre", aunque obra de una segunda fase y, por lo tanto, de los Santa Cruz.

125 Art. cit., p. 60-63: Marías supuso dos fases, la anterior a los Santa Cruz y lo realizado por ellos, que habrían concluido la obra. Adelantándose a una tercera fase: R. González Ramos, La Universidad..., ob. cit., p. 33. Últimamente, un análisis de proximidad de las yeserías viene a confirmar las fases que indican los documentos: C. Martín Jiménez, ob. cit., pp. 551-579.

126 AHN, Universidades, libro 745 , fol. 36 v.
127 AHN, Universidades, loc cit., fols. 20 r, 23 v y 157 v.

128 R. González Ramos, La Universidad..., ob. cit., p. 31.

129 AHN, Universidades, libro 745 , fol. $133 \mathrm{~V}$

130 R. González Ramos, art cit., pp. 387-388

131 J. García Oro, La Universidad..., ob. cit., p. 80. J. García Oro, El Cardenal..., ob. cit., p. 263.

132 M. Á. Castillo Oreja, ob. cit., pp. 51-52 y 124-25; J. García Oro, La Universidad..., ob. cit., p. 87. J. García Oro, El Cardenal..., ob. cit., p. 270; F. Marías Franco, art. cit., p. 59. Los retablos, su número y distribución: $R$. González Ramos, art. cit., pp. 385-411; R. González Ramos, La Universidad..., ob. cit., pp. 44-47.

133 F. Marías Franco, art. cit., p. 60. R. González Navarro, Universidad complutense. Constituciones originales cisnerianas, s. e., Alcalá de Henares, 1984, p. 96.

134 R. González Ramos, art. cit., pp. 385-411; R. González Ramos, La Universidad..., ob. cit., p. 102. 
La construcción de la iglesia del Colegio Mayor de San lldefonso. Las capillas y las yeserías

\section{REFERENCIAS}

Abad Castro, María del Carmen. 1991. Arquitectura mudéjar religiosa en el arzobispado de Toledo. Toledo: Caja de ahorros.

Camón Aznar, José. 1945. La arquitectura plateresca. Madrid: Consejo Superior de Investigaciones Científicas. https://doi.org/10.1080/00 043079.1946.11408440

Cantó Rubio, Juan. 1980. "Oriente y occidente en el estilo Cisneros." In V Simposio Toledo Renacentista, 149-62. Toledo: Colegio Universitario de Toledo.

Castillo Oreja, Miguel Ángel. 1980. El Colegio Mayor de San Ildefonso de Alcalá de Henares. Madrid: Edascal.

Castillo Oreja, Miguel Ángel. 1985. "La proyección del arte islámico en la arquitectura de nuestro primer Renacimiento: El estilo Cisneros." Anales del Instituto de Estudios Madrileños 12: 55-63.

Chueca Goitia, Fernando. 1953. Arquitectura del siglo XVI. Ars Hispaniae XI. Madrid: Plus Ultra.

Díez del Corral, Rosario. 1987. Arquitectura y mecenazgo. La imagen de Toledo en el Renacimiento. Madrid: Alianza.

Dolphin, Erika. 2008. Archbishop Francisco Jiménez de Cisneros and the Decoration of the Chapter Room and Mozarabic Chapel in Toledo Cathedral. Ann Arbor, Michigan: University of Michigan.

Estella Marcos, Margarita. 1985. "Noticias artísticas de Torrelaguna." Boletín del Seminario de Arte y Arqueología 51: 305-17.

García Oro, José. 1988. "El primitivo solar académico complutense." Anales Complutenses 2: 71-82.

García Oro, José. 1992. El Cardenal Cisneros. Vida y empresas. Madrid: Biblioteca de Autores Cristianos.

García Oro, José. 1992. La Universidad de Alcalá de Henares en su etapa fundacional (14581578). Santiago de Compostela: s. e.

González Navarro, Ramón. 1987. "Nuevas aportaciones a medio siglo de construcción uni- versitaria en Alcalá de Henares (1510-1560)." Anales Complutenses 1: 137-66.

González Navarro, Ramón. 1984. Universidad complutense. Constituciones originales cisnerianas. Alcalá de Henares: s. e.

González Navarro, Ramón. 2006. En torno a 1547: la Alcalá de Cervantes. Madrid: Alpuerto.

González Navarro, Ramón. 2013. “Los edificios fundacionales del Colegio Mayor de San Ildefonso y Universidad de Alcalá." In Restauración Contemporánea, edited by J. Rivera, 30346. Alcalá de Henares: Universidad de Alcalá.

González Ramos, Roberto. 2000. "Juan de Borgoña y los retablos de la iglesia de San Ildefonso de la Universidad de Alcalá." Madrid. Revista de Arte, Geografía e Historia 3: 385-411.

González Ramos, Roberto. 2007. La Universidad de Alcalá de Henares y las artes. Alcalá de Henares: Universidad de Alcalá.

González Ramos, Roberto. 2016. La Aldehuela de Torrelaguna. Granja, Colegio, residencia de la Universidad de Alcalá. Alcalá de Henares: Universidad de Alcalá. https://doi.org/10.5209/ anha. 54048

Lope Huerta, Arsenio. 2001. La Sociedad de Condueños, 1850-2000. Alcalá de Henares: Centro Internacional de Estudios Históricos Cisneros.

Marías Franco, Fernando. 1989. El largo siglo XVI. Madrid: Taurus.

Marías Franco, Fernando. 1994. "Pedro de Gumiel, Francisco de Carabaña, la Universidad de Alcalá y el mito del <<estilo Cisneros>>." Boletín del Museo e Instituto "Camón Aznar" 58: 49-80.

Martín Jiménez, Carlos. 2013. "Los velos de la obra. Lectura de la capilla de San Ildefonso a través de sus yeserías." In Restauración Contemporánea, edited by J. Rivera, 551-80. Alcalá de Henares: Universidad de Alcalá.

Meseguer Fernández, Juan. 1982. El Cardenal Cisneros y su villa de Alcalá de Henares. Alcalá de Henares: Institución de Estudios Complutenses. 
Muñoz Santos, María Evangelina. 2002. Las artes decorativas en Alcalá de Henares. Alcalá de Henares: Universidad de Alcalá. https://doi. org/10.1093/gao/9781884446054.article. t001614

Navarro Echeverría, Pilar. 1995. “Presencia toledana en las yeserías mudéjares aragonesas del siglo XVI." Sharq al-Andaluls 12: 519-533. https://doi.org/10.14198/shand.1995.12.31

Pavón Maldonado, Basilio. 1982. Alcalá de Henares medieval. Arte Islámico y mudéjar. Madrid:
Instituto de Estudios Árabes "Miguel Asín"Asociación Cultural Henares.

Quintana Gordon, José Luis de la. 2013. "Materia y significado: las obras de restauración de la manzana fundacional de la Universidad de Alcalá entre 2010 y 2013." In Restauración Contemporánea, edited by J. Rivera, 613-49. Alcalá de Henares: Universidad de Alcalá.

Tormo y Monzó, Elías. 1917. "Cartillas excursionistas Tormo. Alcalá de Henares." Boletín de la Sociedad Española de Excursiones 25: 143-52. 